\title{
Assessment of Quality of Service of Mobile Network Operators in Akure
}

\author{
Obe Olumide Olayinka ${ }^{1}$, Sangodoyin Oluranti Olukemi ${ }^{2} \&$ Otti Chukwuemeka $^{1}$ \\ ${ }^{1}$ Federal University of Technology, Akure, Nigeria \\ ${ }^{2}$ Gaborone Institute of Professional Studies (GIPS), Botswana \\ Correspondence: Sangodoyin Oluranti Olukemi, Gaborone Institute of Professional Studies (GIPS), Botswana.
}

Received: March 22, 2019

doi:10.5430/ijba.v10n3p118
Accepted: May 7, 2019

Online Published: May 9, 2019

URL: https://doi.org/10.5430/ijba.v10n3p118

\begin{abstract}
This study assessed and compared the Quality of Service provided by the four major Mobile Network Operators(MNOs) in Akure, Nigeria as well as assessed their level of compliance with Nigerian Communications Commission standard. The study also examined the level of customer satisfaction on the services delivered by the MNOs. The effect of Quality of Service on the satisfaction of the customers of the MNOs was also investigated in this study.

Primary data was collected in this study using both the drive test and survey questionnaire techniques. The drive test technique was used to collect data on the Quality of Service provided by the MNOs while the survey questionnaire was used to collect data on customer satisfaction from 527 respondents.

Descriptive statistics was used to assess the level of Quality of Service provided and also to examine the level of customer satisfaction. The one-way ANOVA was adopted to compare the Quality of Service provided among the MNOs while Regression analysis was used to examine the effect of Quality of Service on customer satisfaction.

The study revealed that the Quality of Service of the Mobile Network Operators in Akure differed significantly $(\mathrm{P}<0.05)$. It also revealed a moderate level of satisfaction among the customers. Though the Quality of Service provided by the Mobile Network Operators was found not to meet Nigerian Communications Commission standard for most of the key performance indicators, MTN was found to be the best. The study also revealed that the effect of Quality of Service on the satisfaction of customers is insignificant. The study recommended that the Mobile Network Operators should build more base stations as this would help reduce coverage gaps and blind spots and ultimately increase their network coverage.
\end{abstract}

Keywords: quality of service, Nigerian Communications Commission, call setup success rate, call drop rate, handover success rate, retainability rate, customer satisfaction

\section{Introduction}

The introduction of Global System for Mobile Communication (GSM) in Nigeria in 2001 has meaningfully imparted the lives of Nigerians (Momodu \&Akpamu, 2014).Over the years, the mobile network providers in Nigeria have witnessed a tremendous increase in their subscriber base (Alabar et al, 2017). As the number of services and subscribers increased, the demand for good quality of service $(\mathrm{QoS})$ arose. It became very important for mobile network providers to monitor and measure the quality of service of their network accurately with a view to improving them in the most effective and cost-efficient way to achieve customer loyalty and maintain competitive edge.

Customer satisfaction is very important to gain a sustainable competitive edge in the market (Carlos, Otero, Luis, \& Scott,2010; Kadioglu, Dalveren\& Kara, 2015). No matter how well mobile network operators believe their networks are performing, they can still lose subscribers who are not happy with the quality of service delivered. From the perspective of the user, it is very important that there is a guarantee of the utility with respect to the experience regardless of the access platform. However, in spite of the deep penetration and the high technical limits due to the complexities associated with cellular networks, users may frequently not see the top performance of the underlying technology. Difficulty in setting up calls, poor voice quality during calls and dropped calls are some of the frustrations that users have to bear with and often times pay for (Dahunsi\&Kolawole, 2015). 
According to Gajanan and Deshmukh (2013), some people in a particular area may become frustrated when communicating over a cellular network in which they can hardly hear whom they are talking to and sometimes may result in dropped call. This is highly undesirable because subscribers want to get good or high quality of service for paying high bills. The fact that communication plays a pivotal role in today's world is incontrovertible and to support it, quality of service has to be given maximum priority.

Quality of service (QoS) generally can be defined as the level of satisfaction a customer or an end-user derives from a service. In cellular networks, it is the performance of a mobile network, particularly as perceived by the users of the network. QoS is usually measured via a set of metrics called Key Performance Indicators (KPIs).KPIs are calculated from measurements of various network parameters. KPIs are a set of specific requirements provided by a mobile network to users, which are necessary in order to achieve the required functionality of a particular service. KPIs help define the performance metrics of a network.

According to the Nigerian Communications Commission (NCC,) the KPIs used as standards in the assessment of QoS provided by Mobile Network operators include: Call Setup Success Rate (CSSR), Radio Signal Quality and Strength (RX), Call Drop Rate (CDR), Traffic Channel congestion Rate (TCH-CONG), Standalone Dedicated Control Channel Congestion Rate (SDCCH-CONG), Handover Success Rate (HOSR) (Nigerian Communication Commission, 2015; Aninyie, 2012).

\subsection{Statement of the Problem}

The adoption of the GSM in Nigeria is a long awaited development expected in the telecommunication industry (Adegoke, Babalola, \& Balogun, 2008). It was expected that its introduction will bring about effective telecommunication services that will support good speech quality, roaming, spectral efficiency, and minimized crosstalk, just to mention few items (Adegoke, Babalola, \&Balogun, 2008). Its deployment into the market was well embraced by Nigerians and found to be relatively efficient. Sadly, this efficiency is now being hampered by some factors leading to a fall in the quality of services offered by the mobile network providers (Adegoke, Babalola, $\&$ Balogun, 2008).

One of the reasons for the establishment of telecommunication industry is to create satisfaction for the use of the services in all spheres of life while realizing the profit motives. However, there had been complaints from users about the quality of service delivery of the mobile network providers in Nigeria. In spite of the appreciable growth and expansion recorded in the industry, the quality of service is still believed to be below standard.

The focus areas of many organizations are now changing from profit maximization through increased customer satisfaction. The competition pressures are forcing the organizations to not only look at the processes but also the way telecommunication firms deliver their products/services through quality service delivery (Abd-Elrahman, 2018). Over the past two decades, business scenario has changed tremendously. Some of those key changes have necessitated that services must be delivered to customers better than the competitors. Hence, the concept of quality service requires a new understanding in the current mobile telecommunication business scenario (Abd-Elrahman, 2018).

Previous studies have shown that organizations which provide competitive service quality have a lot to satisfy their customers (Shafiq, Shafiq, Din \& Cheema, 2013). This prompts customers to repurchase which is the base of satisfaction and can increase a firm's revenue and profits. This makes the issue of customer satisfaction and service quality very important for research, particularly nowadays that every firm tries to improve its quality of service for customer retention and satisfaction (Gilbert \&Veloutsou, 2006).

Despite the numbers of researches showing the benefit of quality service on customer satisfaction and profit maximization among firms (Shafiqet al., 2013; Gilbert \& Veloutson, 2006), there are limited number of studies on the effect of quality of service on customer satisfaction in the mobile network telecommunication sector. Many of the previously conducted studies were done in hospitality industry (Shafiqet al., 2013), banking industry (Dawit\& Aden, 2018) and health industry. There is also a shortage of empirical studies on the mobile network service providers in developing nations like Nigeria. Therefore, assessing the effect of quality of service on customer satisfaction in the Mobile network service providers' sector in Nigeria is warranted.

\subsection{Objectives of the Study}

(a) To assess the level of the quality of service provided by the mobile network operators in Akure and their level of compliance with NCC standard; 
(b) To examine the level of customer satisfaction on the services delivered by the mobile network operators in Akure;

(c) To compare the quality of service provided among the four mobile network operators in Akure;

(d) To investigate the effect of quality of service on the satisfaction of the customers of mobile network operators in Akure.

\subsection{Research Questions}

(a) What is the level of the quality of service delivered by the various mobile network operators in Akure as well as their level of compliance with the NCC standard?

(b) What is the level of customer satisfaction on the services delivered by the mobile network operators?

(c) What is the difference in the quality of service provided by the four mobile network operators in Akure?

(d) What is the effect of quality of service on the satisfaction of the customers of mobile network operators in Akure?

\section{Review of Literature}

The concept of customer satisfaction has been given different definitions by different authors. However, there is still lack of consensus about the subject matter among researchers (Agyapong, 2010). For example, Rust and Oliver (1994) suggest that customer satisfaction is a "cognitive or affective reaction" - emerges as a response to a single or prolonged set of service encounters. According to Giese and Cote (2000), consumer satisfaction comprises three basic components including the type of response (cognitive, or emotional); the subject on which the response is focused; and the time at which the evaluation is made. But Anderson and Fornell (1994) are of the opinion that the literature is not explicit about the distinction between quality and satisfaction. Satisfaction is a "post consumption" experience which compares perceived quality with expected quality, whereas service quality refers to a global evaluation of a firm's service delivery system (Agyapong, 2010).

Customer satisfaction is conceptualized as an overall, customer attitude towards a service provider. Also customer satisfaction has been described as an effective response, focused on product performance compared to some repurchase standard during or after consumption (Halstead et al., 1994). Also, Mano and Oliver (1993) established that satisfaction is an attitude or evaluative judgement varying along the hedonic continuum focused on the product, which is evaluated after consumption.

Authors have suggested that the difference between customers' expectations about quality of service is a function of their perception about the services. Hence, the first step taken by firms in satisfying the customers is to assess their quality of service (Agyapong, 2010).

Dahunsi and Kolawole (2015), worked on participatory Analysis of Cellular Network Quality of Service. This paper proposed a model for crowdsourcing the evaluation of the quality of service (QoS) provided by Mobile Network Operators (MNOs) in cellular networks. It aimed at addressing the gap between the reported technical capabilities of the telecom infrastructure and the QoS experienced by user. The analysis is based on sets of location-specific network measurements obtained from mobile devices of volunteer users within the network. A crowdsourcing platform was designed to gather a sufficiently large dataset of measurements obtained from the volunteer mobile devices. The data when collated, evaluated and analyzed can be compared against the key performance indicators (KPI) benchmarks set by the Nigerian Communications Commission.

The application is designed to collect, collate and analyze the relevant network data. However, the app is limited in that it cannot differentiate between a dropped call and a legitimately terminated call. The app could detect and indicate congestion but not its cause.

Lawal et al. (2016) carried out a research titled "Quality of Service and Performance Analysis of a GSM Network in Eagle square, Abuja and its environs". The paper distinguished between Quality of Service (QoS) and Quality of end-user Experience (QoE) which is the two major techniques used for judging the performance of GSM services. While the former is adjudged by service providers, the latter is determined by reaction from end-users (subscribers).

The objective of the study was to assess the performance and Quality of service provided by MTN to the famous national historical centre called the Eagle square and its environs in Abuja before, during and after PDP presidential primary elections. The study utilized five major KPIs namely: Call Setup Success Rate (CSSR), Call Drop Rate (CDR), Handover Success Rate (HOSR), Traffic Channel Congestion Rate (TCHCR) and Control Channel Setup Failure (CCSF). 
The Network Statistics method was used to collect data because the data are obtained through in-situ measurements that do not require any pre-mathematical processes and are thus more reliable and subject to less error. Traffic data of MTN's three base stations covering Eagle square and environs from January 10 to January 15, 2011 were retrieved from the Base Station Controller (BSC) and their KPIs were thoroughly analyzed using various statistical tools and compared with NCC recommended values. Results showed that the KPIs deviated from the NCC recommended values and thus the QoS requires an uncompromising improvement in order to curtail further degradation in the services derived by the rapidly increasing subscribers. The limitation of this study is that only one mobile network provider was considered.

Adekitan (2014) reviewed the performance evaluation of global system for mobile telecommunication networks. The study identified power supply and infrastructure as the major challenges retarding the performance of GSM operators in Nigeria. The study concluded that Quality of service, network accessibility, and coverage of GSM in Nigeria are unreliable and unsatisfactory. It recommended that operators should upgrade and optimize all existing base stations which will stem call setup failures due to rise in traffic volumes. It also recommended the installation of additional base stations across the country which would create room for the network to handle more traffic. Finally, it recommended that incessant power failures should be addressed by the government to reduce the over-dependence on generators for power supply.

Adegoke and Babalola (2011), carried out a research titled "Quality of Service analysis of GSM Telephone System in Nigeria". The objective of this study was to evaluate the performance of GSM operators in Nigeria, examine the problems facing the industry as well as suggest methods of improvements.

In this study, an earlier survey carried out by NCC was reviewed. The study focused on Network accessibility, Network retainability and voice quality for three major operators (MTN, Glo and Airtel) in Nigeria. The study revealed that all the networks performed fairly well in terms of network accessibility but did poorly in terms of network retainability and voice quality.

The paper identified instability in power supply, security of infrastructure, call setup failure, call retention and congestion as the problems facing the industry. It then suggested that to tackle those problems, operators should upgrade and optimize their base stations, install more base stations, build additional switching centres, invest well in transmission network development and have a proper radio planning, while government ensures there is stable power supply. The limitation of this study is that it is not recent and it did not consider all the major operators.

Agyapong (2010), carried out a study titled "The Effect of Service Quality on Customer Satisfaction in the Utility Industry - A Case of Vodafone (Ghana)". The study examined the relationship between service quality and customer satisfaction in the utility industry (telecom) in Ghana. The study adopted the SERVQUAL model as the main framework for analyzing service quality. Multiple regression analysis was used to examine the relationships between service quality variables and customer satisfaction. The results showed that all the service quality items were good predictors of customer satisfaction.

Shafiqet al. (2013) carried out a research titled "Impact of Service Quality on Customer Satisfaction: A Study of Hotel Industry of Faisalabad, Pakistan". The study evaluated the hotels' service quality through customer satisfaction. The SERVPERF tool was adopted and administered to customers who stayed in the hotels of Faisalabad, Pakistan. The results indicates that in Pakistan among the five dimensions of SERFPERF, the dimension tangible and empathy needed to be focused on more.

Abd-Elrahman (2018) carried out a study titled “A Review of Telecommunications Service Quality Dimensions". The purpose of the study was to review the service quality dimensions established in various empirical studies conducted across the world specifically applied to Telecommunications services. The study reviewed only empirical studies based on survey data and statistical methods of analysis since 2001 till 2017. The findings revealed that the meaning of service quality may have some universal aspects, as demonstrated by the similarities in the underlying dimensions as proposed in the different studies. The study also lent support to the contention that the dimensionality of SERVQUAL and importance of the dimensions vary with the cultural and country context even within the Telecommunications industry.

\section{Methodology}

This study adopted the use of quantitative research approach conducted in a cross-sectional design. The choice of this research approach is informed owing to the nature of the aim of the study which tended towards assessing the quality of service (QoS) provided by Mobile Network Operators in Akure, Nigeria. The study is quantitative in nature due to the nature of the data collected and which was analyzed statistically to deduce inference and 
generalization about a larger sample. The cross-sectional design of the study indicates that data was collected at a particular period of the study. The study adopted the use of a drive test technique and survey questionnaire to collect data from the respondents.

The choice of Akure was informed because of the continuous increase in population of the city due to improvement in infrastructure and recent development. The study was also limited to the four major mobile network operators (Glo, Etisalat, Airtel and MTN) operating in Nigeria.

The total population of the study is 242249 with MTN having 96211 customers, GLO has 91518, Airtel has 37301 and 9Mobile has 17219.

A sample size of 490.85 was determined and used for the study using the formula presented by Krejcie and Morgan (1970). The study used both cluster sampling technique and stratified random sampling technique to elicit information about quality of services and customer satisfaction in this study respectively. The total population of the study was divided into four strata based on the proportion contributed by each mobile network service provider. Then, simple random technique was later used to select the proportion of the sample size from each stratum of the firms. The cluster technique was used to collect information about quality of services rendered by the mobile network service providers. This involved classifying the study area from which data was collected about quality of services into different clusters.

Primary data was collected in this study using both drive test and survey questionnaire technique. The drive test technique of data collection was used to collect data on quality of services provided by the mobile network operators. The test was performed for benchmark of Airtel, MTN, GLO and 9mobile services. The drive test was carried out in the selected areas and relevant data collected. The drive test was performed using the TEMS (Transmission Environmental Monitoring System) investigation tools which include a laptop with TEMS investigation software fully installed, four Sony Ericsson W995 phones, Garmin GPS and an inverter. The drive test data (log files) was collected and the report generated using MapInfo software.

In addition, data was collected on customer satisfaction using survey questionnaire which was self-administered to the selected number of respondents from the total population of the study. The survey questionnaire consists of close ended questions designed on a five-point Likert scale (1 - Highly unsatisfied to 5 - highly satisfied) which allowed the respondents to state their extent of satisfaction to the services provided by the mobile network operators.

The primary data collected in this study was analyzed using descriptive and inferential statistics through Statistical Package for Social Sciences (SPSS) version 25. The descriptive analysis involved the frequency and mean values. The results were presented in form of Tables and figures. The inferential statistics which include one-way analysis of variance (ANOVA) and multiple regression analysis was also conducted. The one-way ANOVA was used to compare the quality of services provided among the mobile network operators in Akure, while regression analysis was conducted to examine the effect of QoS on customer satisfaction in Akure.

\section{Results and Discussion}

\subsection{Response Rate}

The response rate of the study shows that 527 valid responses was collected out of the total 700 survey questionnaire distributed resulting to $75.29 \%$ response rate.

\subsection{Demographic Characteristics of the Respondents}

The frequency distribution of the respondents shows that majority of the respondents are male $(66.8 \%)$ and $33.2 \%$ are female. Also, $52.8 \%$ of the respondents are subscribed to both Globacom and MTN network and these mobile network operators have the highest number of subscribers in the study area. This is followed by MTN and Airtel network which has $27.7 \%$ numbers of subscription among the respondents. Followed by MTN and 9Mobile with $15.6 \%$ representation. The result shows that customers who uses both 9Mobile and Airtel network has 3\% representation, while Airtel and Globacom both have $0.9 \%$ representation which is the lowest number of subscription by the respondents. However, it is surprising to observe that no respondent subscribed to only one mobile network among the respondents.

Furthermore, the frequency distribution result shows that MTN has the largest representation as the major service providers subscribed by the respondents with $86.1 \%$ representation. This is followed by Globacom and Airtel which both have $4.9 \%$ representation. 9Mobile has the lowest representation with $4.0 \%$ representation. In addition, the inquiry into how long the respondents have been subscribing to the network mobile operators indicates that the majority $(54.8 \%)$ of the respondents have been using the mobile network operators between $5-10$ years, followed 
by $17.6 \%$ who have just started to use the mobile network service operators in less than 5 years. $16.5 \%$ have been using it between $11-15$ years, while $11.1 \%$ have been using it for over 15 years.

Furthermore, the frequency distribution result shows that MTN has the largest representation as the major service providers subscribed by the respondents with $86.1 \%$ representation. This is followed by Globacom and Airtel which both have $4.9 \%$ representation. 9Mobile has the lowest representation with $4.0 \%$ representation. In addition, the inquiry into how long the respondents have been subscribing to the network mobile operators indicates that the majority $(54.8 \%)$ of the respondents have been using the mobile network operators between $5-10$ years, followed by $17.6 \%$ who have just started to use the mobile network service operators in less than 5 years. $16.5 \%$ have been using it between $11-15$ years, while $11.1 \%$ have been using it for over 15 years.

\subsection{Level of Customer Satisfaction}

The evaluation of customer satisfaction (CS) in this study was done through the descriptive analysis using the mean value and standard deviation of the data collected. The description of the satisfaction of customers as presented in Table 1 below revealed a minimum value of 1 and maximum value of 5 for all the items measuring customer satisfaction construct. The mean value $=3.77$ on ' $\mathrm{CS} 2$ ' and mean value $=3.69$ on CS5 indicates a high level of customers' satisfaction on quality of calls made and rate of calls successfully established. The mean value $=3.48$ for CS1; 3.42 for CS3; 3.58 for CS6; 3.20 for CS8; 3.06 for CS9; 2.94 for CS4 and 2.75 for CS7 indicates a moderate customers' satisfaction on quality of service provided, network availability, overall delivery of services, feedback from the customer care agencies, response to network issues by service providers, rate of call drop while making calls and the time taken by customers to respond to customer calls. The standard deviation values are all above 1, indicating that the responses are diverse among the customers.

Table 1. Level of customer satisfaction

\begin{tabular}{lllllll}
\hline $\mathbf{S} / \mathbf{N}$ & Code & Description & Min & Max & Mean & Std. Dev \\
\hline $\mathbf{1}$ & CS1 & $\begin{array}{l}\text { The quality of services provided by your } \\
\text { service providers }\end{array}$ & 1 & 5 & 3.48 & 1.005 \\
\hline $\mathbf{2}$ & CS2 & The quality of calls made & 1 & 5 & 3.77 & 1.049 \\
\hline $\mathbf{3}$ & CS3 & Network availability of your service provider & 1 & 5 & 3.42 & 1.081 \\
\hline $\mathbf{4}$ & CS4 & Rate of call drop while making calls & 1 & 5 & 2.94 & 1.240 \\
\hline $\mathbf{5}$ & CS5 & Rate of calls successfully established & 1 & 5 & 3.69 & 1.179 \\
\hline $\mathbf{6}$ & CS6 & $\begin{array}{l}\text { Overall delivery of services by your service } \\
\text { provider }\end{array}$ & 1 & 5 & 3.58 & 1.054 \\
\hline $\mathbf{7}$ & CS7 & Response time to customer's inquiry & 1 & 5 & 2.75 & 1.181 \\
\hline $\mathbf{8}$ & CS8 & $\begin{array}{l}\text { Feedback from customer care agents of your } \\
\text { service providers }\end{array}$ & 1 & 5 & 3.20 & 1.200 \\
\hline $\mathbf{9}$ & CS9 & $\begin{array}{l}\text { Response to network issues by your service } \\
\text { providers }\end{array}$ & 1 & 5 & 3.06 & 1.184 \\
& & & & & \\
\hline
\end{tabular}

Note: $1.00-2.40=$ Low satisfaction; $2.41-3.60=$ Moderate satisfaction; $3.61-5.0=$ High satisfaction

\subsection{Level of Quality of Service}

The level of Quality of service (QoS) among the mobile network service operators are presented using frequency analysis and mean values of the Rxlevel and Quality distribution.

Figure 1 shows the Average Rx Levels for Airtel, MTN, GLO and 9Mobile in Akure South Local Government Area. Only Rx Levels that are greater or equal to $-90 \mathrm{dBm}$ are acceptable. Table 2 shows that in Akure South LG, 9Mobile has the best Rx Levels while that of Airtel is the worst. 


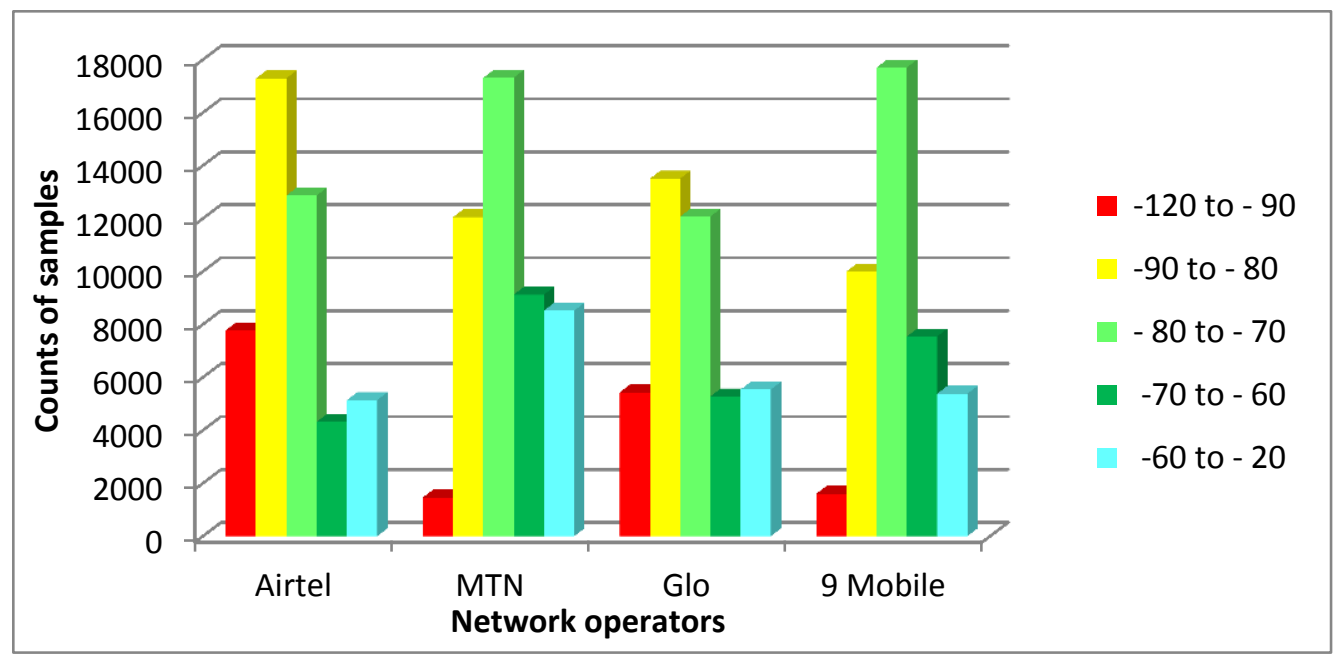

Figure 1. Summary of Rx level (dBm) in Akure South LG

Table 2. Rx level ranking for Akure South LG

\begin{tabular}{|c|c|c|}
\hline \multirow[b]{2}{*}{ Operator } & Percentag & \multirow[b]{2}{*}{ Rank } \\
\hline & RX LEVEL $\geq-90(\mathrm{dBm})$ & \\
\hline Airtel & $83.96 \%$ & 4th \\
\hline MTN & $96.96 \%$ & 2nd \\
\hline GLO & $86.34 \%$ & $3 \mathrm{rd}$ \\
\hline 9Mobile & $97.09 \%$ & $1 \mathrm{st}$ \\
\hline
\end{tabular}

Figure 2 shows the Average Rx Quality for Airtel, MTN, GLO and 9Mobile in Akure South Local Government Area. Only Rx Quality values that are less or equal to 6 are acceptable. Figure 2 also shows that all the operator networks have most of their Rx Quality between $0-3 \mathrm{db}$ which is very good. The counts and percentage of Airtel, MTN, Glo and 9 mobile Rx Quality are (37314 and 83\%), (35859 and 83\%), (26936 and 75\%) and (21869 and 63\%) respectively. Table 3 shows that in Akure South LG, MTN has the best Rx Quality, followed by Airtel while that of 9 Mobile is the worst.

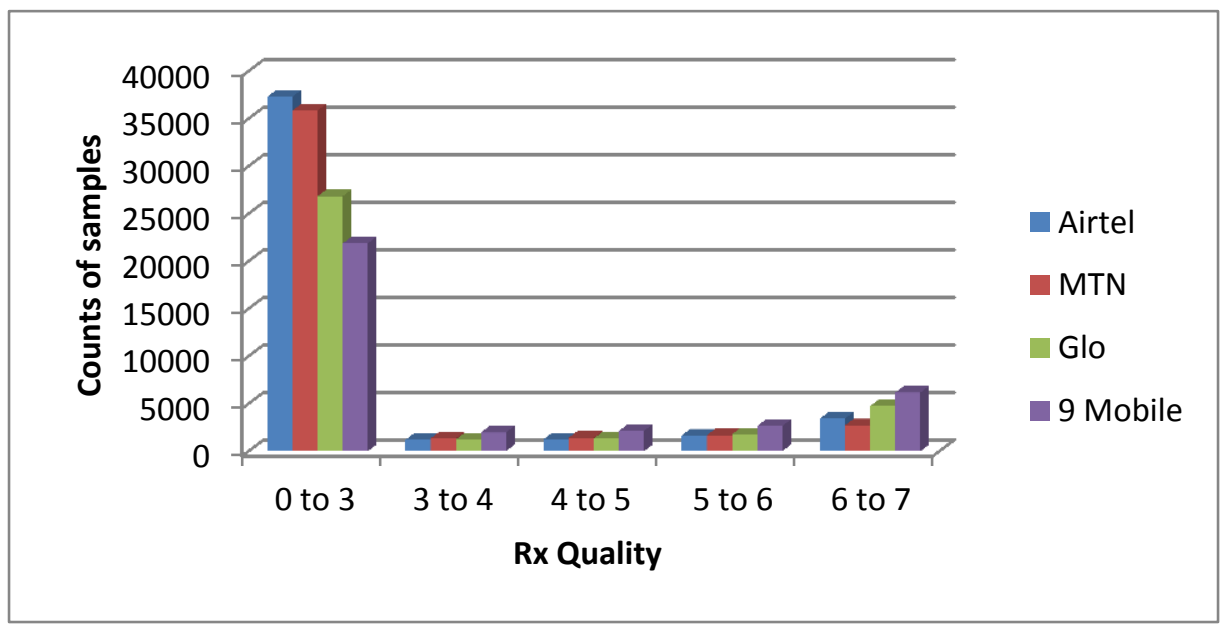

Figure 2. Summary of Rx quality (dB) in Akure South LG 
Table 3. Rx quality ranking for Akure South LG

\begin{tabular}{|c|c|c|}
\hline \multirow[b]{2}{*}{ Operator } & Percentage count of sar & \multirow[b]{2}{*}{ Rank } \\
\hline & RX QUALITY $\leq 6(\mathrm{~dB})$ & \\
\hline Airtel & $92.80 \%$ & 2 nd \\
\hline MTN & $93.70 \%$ & $1 \mathrm{st}$ \\
\hline GLO & $86.03 \%$ & $3 \mathrm{rd}$ \\
\hline 9Mobile & $82.28 \%$ & 4 th \\
\hline
\end{tabular}

Figure 3 shows the Average Rx Levels for Airtel, MTN, GLO and 9Mobile in Akure North Local Government Area. Only Rx Levels that are greater or equal to $-90 \mathrm{dBm}$ are acceptable.

Table 4 shows that in Akure North LG, 9Mobile has the best Rx Levels while that of Airtel is the worst.

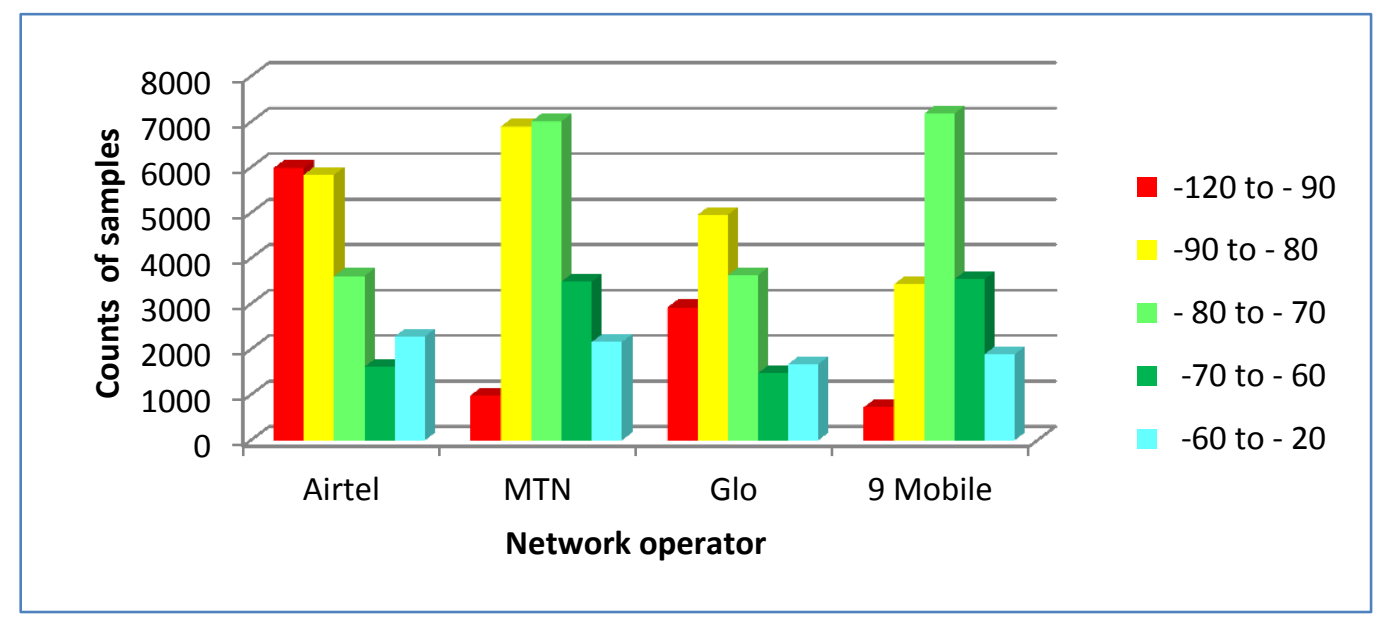

Figure 3. Summary of Rx level (dbm) in Akure North LG

Table 4. Rx level ranking for Akure North LG

\begin{tabular}{|c|c|c|}
\hline \multirow[b]{2}{*}{ Operator } & Percentage count of samp & \multirow[b]{2}{*}{ Rank } \\
\hline & RX LEVEL $\geq-90(\mathrm{dBm})$ & \\
\hline Airtel & $63.48 \%$ & 4th \\
\hline MTN & $94.41 \%$ & 2nd \\
\hline GLO & $76.68 \%$ & $3 r d$ \\
\hline 9Mobile & $95.16 \%$ & $1 \mathrm{st}$ \\
\hline
\end{tabular}

Figure 4 shows the Average Rx Quality for Airtel, MTN, GLO and 9Mobile in Akure North Local Government Area. Only Rx Quality values that are less or equal to 6 are acceptable. Figure 4 also show that all the operator networks have most of their Rx Quality between 0-3db. The counts and percentage of Airtel, MTN, Glo and 9 mobile Rx Quality are (13460 and 77\%), (16983 and 93\%), (8152 and 71\%) and (7079 and 52\%) respectively. Table 5 shows that in Akure North LG, MTN has the best Rx Quality, followed by Airtel while Glo has the worst Rx Quality. 


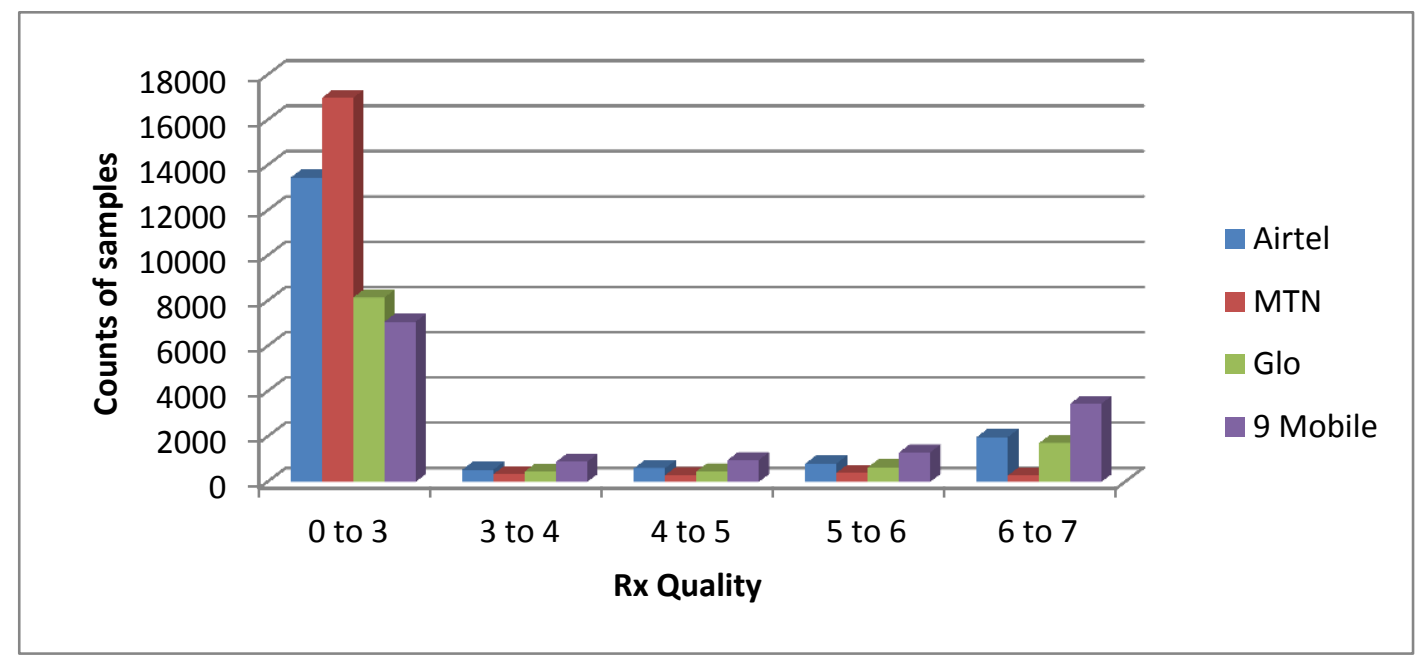

Figure 4. Summary of Rx quality sub (db) in Akure North LG

Table 5. Rx quality ranking for Akure nNorth LG

\begin{tabular}{|c|c|c|}
\hline \multirow[b]{2}{*}{ Operator } & Percentage count of sar & \multirow[b]{2}{*}{ Rank } \\
\hline & RX QUALITY $\leq 6(\mathrm{~dB})$ & \\
\hline Airtel & $85.26 \%$ & 2 nd \\
\hline MTN & $98.26 \%$ & $1 \mathrm{st}$ \\
\hline GLO & $76.20 \%$ & 4th \\
\hline 9Mobile & $80.33 \%$ & $3 \mathrm{rd}$ \\
\hline
\end{tabular}

Table 6 below shows the KPI (Call statistics) Ranking of the Mobile Network Operators in Akure South LG. The table shows that in Akure South LG, with the exception of the Handover Success Rate for which only MTN and Airtel met NCC's standard, all the MNOs failed to meet the NCC's standard for all other KPI parameters.

Table 6. KPI (call statistics) ranking for Akure South LG

\begin{tabular}{llllll}
\hline KPI RANKING & NCC Standard & Airtel & MTN & GLO & 9Mobile \\
\hline CSSR $(\%)$ & $\geq 98$ & 76.26 & 93.99 & 91.71 & 86.00 \\
\hline Drop Call Rate $(\%)$ & $<1$ & 2.04 & 1.21 & 2.25 & 4.35 \\
\hline Handover Success Rate $(\%)$ & $\geq 90$ & 99.49 & 98.92 & 88.27 & 89.04 \\
\hline RetainabilityRate $(\%)$ & $\geq 99$ & 97.96 & 98.79 & 97.75 & 95.65 \\
\hline
\end{tabular}

Table 7 shows theKPI (Call statistics) Ranking of the Mobile Network Operators in Akure North LG. The table shows that in Akure North LG, all the MNOs met NCC's standard for Handover Success Rate. However, for other KPI (Call statistics) parameters, only MTN met NCC's standard. 
Table 7. KPI (call statistics) ranking for Akure North LG

\begin{tabular}{llllll}
\hline KPI RANKING & NCC Standard & Airtel & MTN & GLO & 9Mobile \\
\hline CSSR $(\%)$ & $\geq 98$ & 80.32 & 98.75 & 78.11 & 85.72 \\
\hline Drop Call Rate $(\%)$ & $<1$ & 4.50 & 0.00 & 15.83 & 4.07 \\
\hline Handover Success Rate $(\%)$ & $\geq 90$ & 100.00 & 100.00 & 100.00 & 100.00 \\
\hline RetainabilityRate $(\%)$ & $\geq 99$ & 95.50 & 100.00 & 84.17 & 95.92 \\
\hline
\end{tabular}

These results show that the Quality of service offered by the MNOs is quite poor.

\subsection{Comparative Analysis of the Quality of Service Among the Service Providers}

The distributions of the collected signal samples of Rx Level and Rx Quality for Network operators in Akure North LG are shown in Table 8. The result shows that the signal samples of Rx Level and Rx Quality for the network operators differ significantly $(\mathrm{p} \leq 0.05)$. 9 mobile and MTN have the highest proportion of signal samples of Rx Level $(\geq=-90 \mathrm{dbm}(95.16 \%))$ and Rx Quality $(\leq 6 \mathrm{db}(98.26 \%))$ respectively. Airtel and Glo have the lowest proportion of signal samples of Rx Level $(\geq=-90 \mathrm{dbm}(63.48 \%))$ and Rx Quality $(\leq 6 \mathrm{db}(76.20 \%))$ respectively.

Table 8. Rx level and Rx quality distribution of collected samples in Akure North LG

\begin{tabular}{lll}
\hline Drive Test & Percentage of samples \\
\cline { 2 - 3 } & Rx Level $(\geq-90 \mathrm{dbm})$ & Rx Quality $(\leq 6 \mathrm{db})$ \\
\hline Airtel & $63.48 \mathrm{~b}$ & $85.26 \mathrm{ab}$ \\
MTN & $94.41 \mathrm{a}$ & $98.26 \mathrm{a}$ \\
Glo & $76.68 \mathrm{ab}$ & $76.20 \mathrm{~b}$ \\
9 Mobile & $95.16 \mathrm{a}$ & $80.33 \mathrm{ab}$ \\
\hline
\end{tabular}

Means of variables in the same column with the same letters are not significantly different $(\mathrm{p}>0.05)$

The distributions of the collected signal samples of Rx Level and Rx Quality for Network operators in Akure South LG are shown in Table 9. The result shows that the signal samples of Rx Level and Rx Quality for the network operators differ significantly ( $\mathrm{p} \leq 0.05) .9$ mobile and MTN have the highest proportion of signal samples of Rx Level $(\geq=-90 \mathrm{dbm}(97.09 \%)$ ) and Rx Quality $(\leq 6 \mathrm{db}(93.70 \%))$. Airtel and 9 mobile have the lowest proportion of signal samples of Rx Level $(\geq=-90 \mathrm{dbm}(83.96 \%))$ and Rx Quality $(\leq 6 \mathrm{db}(82.28 \%))$ respectively. The result from this study was similar to that reported by Rajesh et al. (2014) that most of the samples with Rx Level are within the interval from -85 to $0 \mathrm{dBm}$ with average of $-85 \mathrm{dBm}$. Additionally, about $68 \%$ of the samples have excellent quality corresponding to Rx Quality value of 0 . In addition, about $3 \%$ of the samples have poor quality corresponding to Rx Quality values of 5 and 7.

Table 9. Rx level and Rx quality distribution of collected samples in Akure South LG

\begin{tabular}{lll}
\hline Drive Test & Percentage of samples \\
\cline { 2 - 3 } & Rx Level $(\geq-90 \mathrm{dbm})$ & Rx Quality $(\leq 6 \mathrm{db})$ \\
\hline Airtel & $83.96 \mathrm{~b}$ & $92.80 \mathrm{a}$ \\
MTN & $96.96 \mathrm{a}$ & $93.70 \mathrm{a}$ \\
Glo & $86.34 \mathrm{~b}$ & $86.03 \mathrm{~b}$ \\
9 Mobile & $97.09 \mathrm{a}$ & $82.28 \mathrm{~b}$ \\
\hline
\end{tabular}

Means of variables in the same column with the same letters are not significantly different $(p>0.05)$ 
Table 10 shows the KPI assessment of collected samples for Network operators in Akure North LG. The result shows that KPI assessment indicators for network operators in this study differ significantly $(p \leq 0.05)$ except RR and HOSR values in Akure North LG. MTN has the best CSSR (98.75\%),DCR (0\%) and RR (100\%) values compared to other network operators. The NCC standards for CSSR, DCR and RR were only met by MTN. HOSR for all the network operators is $100 \%$ which shows that HOSR values for different operators did not differ significantly from the NCC standard in Akure North LG.

Table 11 shows the KPI assessment of collected samples for Network operators in Akure South LG. The result shows that KPI assessment indicators for network operators in this study differ significantly $(\mathrm{p} \leq 0.05)$ in Akure South LG. MTN have the best CSSR (93.99\%), RR (98.79\%) and DCR (1.21\%) values while Airtel have the highest HOSR value $(99.49 \%)$ compared to other network operators. None of the network operators met NCC standard for CSSR and DCR in Akure South LG. However, while only Airtel met NCC standard for HOSR, all the Network operators except 9 mobile met NCC standard for RR.

All KPIs for Akure South LG differ significantly for the network operators while significant differences were only obtained for CSSR and DCR among the network operators in Akure North. Key performance indicator is one of the measures used to evaluate the services provided by GSM networks which are accomplished by monitoring the effectiveness of some network impairments (Alabi et al., 2017).

Table 10. KPI assessment of collected samples in Akure North LG

\begin{tabular}{lllll}
\hline KPI & CSSR $(\%)$ & DCR $(\%)$ & RR $(\%)$ & HOSR (\%) \\
\hline Airtel & $80.32 \mathrm{ab}$ & $4.50 \mathrm{ab}$ & $95.50 \mathrm{a}$ & $100 \mathrm{a}$ \\
\hline MTN & $98.75 \mathrm{a}$ & $0.00 \mathrm{a}$ & $100.00 \mathrm{a}$ & $100 \mathrm{a}$ \\
\hline Glo & $78.11 \mathrm{~b}$ & $15.83 \mathrm{~b}$ & $84.17 \mathrm{a}$ & $100 \mathrm{a}$ \\
\hline 9 Mobile & $85.72 \mathrm{ab}$ & $4.07 \mathrm{ab}$ & $95.92 \mathrm{a}$ & $100 \mathrm{a}$ \\
\hline NCC Standard & $\geq 98$ & $<1$ & $\geq 90$ & $\geq 99$ \\
\hline
\end{tabular}

Means of variables in the same column with the same letters are not significantly different $(\mathrm{p}>0.05)$

Table 11. KPI assessment of collected samples in Akure South LG

\begin{tabular}{lllll}
\hline KPI & CSSR $(\%)$ & DCR $(\%)$ & RR $(\%)$ & HOSR (\%) \\
\hline Airtel & $76.26 \mathrm{c}$ & $2.04 \mathrm{a}$ & $97.96 \mathrm{a}$ & $99.49 \mathrm{a}$ \\
\hline MTN & $93.99 \mathrm{a}$ & $1.21 \mathrm{a}$ & $98.79 \mathrm{a}$ & $98.92 \mathrm{a}$ \\
\hline Glo & $91.71 \mathrm{ab}$ & $2.25 \mathrm{ab}$ & $97.75 \mathrm{ab}$ & $88.27 \mathrm{~b}$ \\
\hline 9 Mobile & $86.00 \mathrm{~b}$ & $4.35 \mathrm{~b}$ & $95.65 \mathrm{~b}$ & $89.04 \mathrm{~b}$ \\
\hline NCC Standard & $\geq 98$ & $<1$ & $\geq 90$ & $\geq 99$
\end{tabular}

Means of variables in the same column with the same letters are not significantly different $(p>0.05)$

\subsection{Effect of QoS on Customer Satisfaction}

The effect of QoS on customer satisfaction was tested in this study through regression analysis. Table 12 presents the result of the regression analysis. The result of the regression analysis as shown in the model summary indicates $\mathrm{R}$ value of 0.12 and $R$ square value of 0.01 indicating that Quality of service (QoS) measured by Receive level (RXL), Receive quality (RXQ), call setup success rate (CSSR), dropped calls rate (DCR), retainability rate (RR) and handover success rate (HOSR) explained about 1\% variance in customer satisfaction. The remaining 99\% variance is explained by factors that are not included in this result. This indicates that the contribution of quality of service to customer's satisfaction among network mobile service operators is insignificant. Hence, customer's satisfaction goes beyond only quality of services but other services not included in this study. 
Table 12. Model summary

\begin{tabular}{lllll}
\hline Model & $\mathrm{R}$ & R Square & $\begin{array}{l}\text { Adjusted } \\
\text { Square }\end{array}$ & $\begin{array}{l}\text { RStd. Error of the } \\
\text { Estimate }\end{array}$ \\
\hline 1 & $.115^{\mathrm{a}}$ & .013 & .003 & .66691 \\
\hline \multicolumn{4}{l}{ a. Predictors: (Constant), KPI, RXL, RXQ, RR, CSSR } \\
\hline
\end{tabular}

Table 13 presents the analysis of variance of QoS on customer satisfaction. The result shows a significant value of 0.539 which is greater than the significant level of 0.05 indicating that the model is insignificant. Further result as shown in Table 14 revealed the standard beta value of the construct. The result shows that RXL has a beta value = -0.03; RXQ $=0.02$; CSSR $=0.12$, and RR $=-0.08$. these indicate that the contribution of $\mathrm{QoS}$ to customer satisfaction in Mobile network service provider is very weak and minute.

Table 13. ANOVA for the effect of QoS on customer satisfaction

\begin{tabular}{|c|c|c|c|c|c|c|}
\hline Model & & Sum of Squares & $\mathrm{df}$ & Mean Square & $\mathrm{F}$ & Sig. \\
\hline \multirow{3}{*}{1} & Regression & 1.815 & 5 & .363 & .816 & $.539^{\mathrm{b}}$ \\
\hline & Residual & 135.655 & 305 & .445 & & \\
\hline & Total & 137.470 & 310 & & & \\
\hline \multicolumn{7}{|c|}{ a. Dependent Variable: CS } \\
\hline \multicolumn{7}{|c|}{ b. Predictors: (Constant), KPI, RXL, RXQ, RR, CSSR } \\
\hline
\end{tabular}

Table 14. Coefficient table for the effect of QoS on customer satisfaction

\begin{tabular}{|c|c|c|c|c|c|c|}
\hline \multirow[t]{2}{*}{ Model } & & \multicolumn{2}{|c|}{ Unstandardized Coefficients } & \multirow{2}{*}{$\begin{array}{l}\text { Standardized } \\
\text { Coefficients } \\
\text { Beta }\end{array}$} & \multirow[t]{2}{*}{$\mathrm{t}$} & \multirow[t]{2}{*}{ Sig. } \\
\hline & & $\mathrm{B}$ & Std. Error & & & \\
\hline \multirow{6}{*}{1} & (Constant) & 3.674 & 1.762 & & 2.084 & .038 \\
\hline & RXL & -.003 & .005 & -.033 & -.502 & .616 \\
\hline & $\overline{\mathrm{RXQ}}$ & .002 & .010 & .025 & .254 & .800 \\
\hline & $\overline{\mathrm{CSSR}}$ & .012 & .008 & .161 & 1.468 & .143 \\
\hline & $\overline{\mathrm{RR}}$ & -.008 & .023 & -.031 & -.354 & .724 \\
\hline & $\overline{\mathrm{KPI}}$ & -.006 & .014 & -.048 & -.416 & .678 \\
\hline
\end{tabular}

a. Dependent Variable: CS

One plausible explanation for the insignificant effect of quality of service (QoS) on customer satisfaction might be as a result of the fact that the customers of Mobile network service providers nowadays often use more than one network as revealed in the demographic analysis of the study. This indicates that the QoS is not really a priority to the customer since poor service in one operator's service might not really have effect on the customer since it might be augmented by the other network used by the customer.

The findings of this study corroborate the findings of Popoola et al. (2009) who asserted that quality of services from the Mobile network service providers in Nigeria is unreliable. Therefore, it does not predict the satisfaction of the customer. Even though the level of satisfaction found in this study shows that there is a moderate level of satisfaction among the customers of the mobile network service providers in Akure.

\section{Conclusion}

This study revealed that MTN has the best quality of service in Akure. However, the four Mobile Network Operators are still far from providing reliable services. The performance or Quality of service of these Mobile Network 
Operators is still a far cry from the expectations of the myriad of consumers. The findings of this study corroborate the findings of Popoola et al. (2009) who asserted that quality of services from the Mobile network service providers in Nigeria is unreliable. The result from this study was similar to that reported by Nochiri et al. (2014) that all the operators failed in CSSR rate set threshold by NCC neglecting possible error margins.

In addition, Quality of service of the mobile network operators does not significantly predict customer satisfaction in Akure. The contribution of quality of services to customer satisfaction is insignificant and hence, has a little effect on determining the satisfaction of the customers. Thus, what predicts the satisfaction of customers of the mobile network service operators goes beyond only QoS.

\section{Recommendation}

The Mobile Network Operators should focus on building more base stations in order to increase their network coverage and reduce coverage gaps and blind spots. They should also review their networks and effect some optimization measures. Soft hand over should also be incorporated due to the 'break and make' of hard handover to reduce call drop rate. Handover parameters on neighboring cells should be well defined in order to retain radio connection and reduce dropped calls. Also, neighbors should be defined for all the missing cells in order to reduce dropped calls. Wrong antenna azimuth and swap sectors should also be checked.

The assessment of QoS among the mobile network service providers in this study only covered voice calls. Data services were not considered. This might actually be responsible for the insignificant relationship between QoS and customer satisfaction since the majority of the respondents are students who often prefer chatting to making voice calls. Hence, future researches are encouraged to extend the scope of the study to Data services provided by the firms.

The research was carried out for only $2 \mathrm{G}$ voice calls; it is recommended that further research is done to accommodate $3 \mathrm{G}$ voice calls.

\section{References}

Abd-Elrahman, A. H. (2018). A Review of Telecommunications Service Quality Dimensions. Scholar Journal of Applied Sciences and Research, 1(1), 10-18.

Adegoke, A. S., \& Babalola, I. T. (2011). Quality of service analysis of GSM telephone system in Nigeria. American Journal of Scientific and Industrial Research, 2(5), 707-712. https://doi.org/10.5251/ajsir.2011.2.5.707.712

Adegoke, A. S., Babalola, I. T., \& Balogun, W. A. (2008). Performance evaluation of GSM mobile system in Nigeria. The Pacific Journal of Science and Technology, 9(2), 436-441.

Agyapong, K. Q. (2010). The Effect of Service Quality on Customer Satisfaction in the Utility Industry - A Case of Vodafone (Ghana). International Journal of Business and Management, 6(5), 203-210. https://doi.org/10.5539/ijbm.v6n5p203

Alabar, T. T., Ode, E., \& Gbande, I. R. (2017). Service Quality and Customer Satisfaction in Nigerian Mobile Telephony. British Journal of Marketing Studies, 5(3), 1-13.

Alabi, I. K., Sagir, L., Fatai, O. A., \& Alabi, I. I. (2017). GSM quality of service performance in Abuja, Nigeria. International Journal of Computer Science, Engineering and Applications (IJCSEA), 7, 29-40. https://doi.org/10.5121/ijcsea.2017.7403

Anderson, E. W., \& Fornell, C. (1994). Customer satisfaction, market share and profitability: Findings from Sweden. Journal of Marketing, 58(3), 53-66. https://doi.org/10.1177/002224299405800304

Aninyie, P. (2012). Performance evaluation of a GSM/GPRS cellular network using the CSSR with direct TCH assignment feature. Ghana: Kwame Nkrumah University of Science and Technology, College of Engineering.

Carlos, E., Otero, I. K., Luis, D. O., \& Scott, L. M. (2010). Characterization of user-perceived quality of service (QoS) in mobile devices using network pairwise comparisons. Int. Journal of Wireless and Mobile Networks, 2(3), 141-153. https://doi.org/10.5121/ijwmn.2010.2310

Dahunsi, F. M., \& Kolawole, G. (2015). Participatory analysis of cellular network quality ofservice. International Journal of Computing and ICT Research, 9(1), 25-40.

Dawit, B. J., \& Adem, U. (2018). The Effect of Perceived Service Quality on Customer Satisfaction in Private Commercial Banks of Ethiopia: The Case of Selected Private Commercial Banks at Dire Dawa Administration. Business and Economics Journal, 9(2), 1-4. https://doi.org/10.4172/2151-6219.1000358 
Gajanan, P. U., \& Deshmukh, C. N. (2013). QoS Based CAC Scheme for 3G Wireless Cellular Networks. A Review. International Journal of Computer Science and Applications, 6(2), 181-185.

Giese, J. L., \& Cote, J. A. (2000). Defining Consumer Satisfaction. Academy of Marketing Science Review, 1, 1-27.

Gilbert, G. R., \& Veloutsou, C. (2006). A cross-industry comparison of customer Satisfaction. The Journal of Services Marketing, 20(5), 298-308. https://doi.org/10.1108/08876040610679918

Halstead, D., Hartman, D., \& Schmidt, S. L. (1994). Multisource effects on the satisfaction formation process. Journal of the Academy of Marketing Science, 22(2), 114-129. https://doi.org/10.1177/0092070394222002

Kadioglu, R., Dalveren, Y., \& Kara, A. (2015). Quality of service assessment: a case study on performance benchmarking of cellular network operators in Turkey. Turkish Journal of Electrical Engineering \& Computer Sciences, 23, 548-559. https://doi.org/10.3906/elk-1302-191

Lawal, B. Y., Ukhurebor, K. E., Adekoya, M. A., \& Aigbe, E. E. (2016). Quality of service and performance analysis of a GSM network in Eagle Square, Abuja and its Environs. In Nigeria. International Journal of Scientific \& Engineering Research, 7(8), 1992-1999.

Mano, H., \& Oliver, R. L. (1993). Assessing the dimensionality and structure of the consumption experience: evaluation, feeling, and satisfaction. Journal of Consumer Research, 20(3), 451-466. https://doi.org/10.1086/209361

Momodu, M., \& Akpamu, U. (2014). Global system of mobile communication as tool for information technology among lecturers in college of medicine. Advances in Applied Sciences Research, 5(2), 368-372.

Nigerian Communication Commission. (2015). QoS (Technical) Benchmarks for Mobile Services. Retrieved April 5, 2015, from http://www.ncc.gov.ng

Popoola, J. J., Megbowon, J. O., \& Adeloye, V. S. (2009). Performance Evaluation and Improvement on Quality of Service of Global System for Mobile Communications in Nigeria. JITI Journal of Information Technology Impact., 9, 91-106.

Rust, R. T., \& Oliver, R. L. (1994). Service quality: insights and managerial implications from the frontier. In Rust, R. T. \& Oliver, R. L. (Eds), Service quality: New Directions in Theory and Practice (pp.241-268). https://doi.org/10.4135/9781452229102.n1

Shafiq, Y., Shafiq I., Din, M. S., \& Cheema, K. U. (2013). Impact of Service Quality on Customer Satisfaction: A Study of Hotel Industry of Faisalabad, Pakistan. International Journal of Management \& Organizational Studies, 2(1), 49-53. 